\title{
Construction Management
}

RETRACTION NOTE

\section{RETRACTION NOTE: Exposure Assessment for Roller Compacted Concrete Dam Construction Integrated Real-Time Location Information}

\author{
Xiazhong Zhenga,b, Jiali Zhou ${ }^{\circledR a, b}$, Guoliang Chen ${ }^{\mathrm{a}, \mathrm{b}}$, and Shu Chen ${ }^{\circledR a, b}$ \\ ${ }^{a}$ College of Hydraulic \& Environmental Engineering, China Three Gorges University, Yichang 443002, China \\ ${ }^{b}$ Hubei Key Laboratory of Construction and Management in Hydropower Engineering, China Three Gorges University, Yichang 443002, China
}

Retraction note to: KSCE Journal of Civil Engineering (2020) 24(3):703-714

DOI 10.1007/s12205-020-1163-2

The authors have retracted the article Zheng et al. (2020). After publication, they became aware that the method proposed fails to express the real-time position of the concrete bucket, which leads to the incorrect real-time position of impact space. Because the description of the real-time position is not accurate in the Methods section, the results on exposure frequency are unreliable. All authors agree with this retraction.

\section{Reference}

Zheng X, Zhou J, Chen G, Chen S (2020) Exposure assessment for roller compacted concrete dam construction integrated real-time location information. KSCE Journal of Civil Engineering 24(3):703-714, DOI: 10.1007/s12205-020-1163-2

CORRESPONDENCE Shu Chen $\varangle$ chenshu@ctgu.edu.cn $\square$ College of Hydraulic \& Environmental Engineering; Hubei Key Laboratory of Construction and Management in Hydropower Engineering, China Three Gorges University, Yichang 443002, China

(c) 2021 Korean Society of Civil Engineers 